\title{
Current Pathologic Scoring Systems for Metal-on-metal THA Revisions are not Reproducible
}

\author{
Christiaan Smeekes MD, Arjen H. G. Cleven MD, PhD, \\ Bart C. H. van der Wal MD, PhD, Stefan V. Dubois MD, \\ Remigio W. Rouse MD, Bastiaan F. Ongkiehong MD, \\ Ron Wolterbeek MD, Rob G. H. H. Nelissen MD, PhD
}

Received: 11 January 2017/ Accepted: 23 June 2017/Published online: 7 July 2017

(C) The Author(s) 2017. This article is an open access publication

\begin{abstract}
Background The aseptic lymphocyte vasculitis-associated lesion (ALVAL) score and the modified Oxford ALVAL score are frequently used scoring methods to evaluate the morphologic features of periprosthetic tissues around metal-on-metal (MoM) hip implants. Except for the initial studies of these two morphology scoring methods, to our knowledge, no other studies have reported on intraclass correlation coefficient (ICC) values for interobserver reliability of these scoring methods.
\end{abstract}

Each author certifies that he or she, or a member of his or her immediate family, has no funding or commercial associations (eg, consultancies, stock ownership, equity interest, patent/licensing arrangements, etc) that might pose a conflict of interest in connection with the submitted article.

All ICMJE Conflict of Interest Forms for authors and Clinical Orthopaedics and Related Research ${ }^{\circledR}$ editors and board members are on file with the publication and can be viewed on request.

Clinical Orthopaedics and Related Research ${ }^{\circledR}$ neither advocates nor endorses the use of any treatment, drug, or device. Readers are encouraged to always seek additional information, including FDAapproval status, of any drug or device prior to clinical use.

The scientific committee of the Leiden University Medical Centre and the ethical committee in the Meander Medical Centre waived approval for the human protocol for this investigation, and each author certifies that all investigations were conducted in conformity with ethical principles of research.

This work was performed at Meander Medical Centre, Amersfoort, The Netherlands, and Leiden University Medical Centre, Leiden, The Netherlands.

Electronic supplementary material The online version of this article (doi:10.1007/s11999-017-5432-4) contains supplementary material, which is available to authorized users.

C. Smeekes ( $)$, R. G. H. H. Nelissen

Department of Orthopaedics, Leiden University Medical Center, PO Box 9600, 2300 RC Leiden, The Netherlands

e-mail: c.smeekes@lumc.nl
Questions/purposes Are the ALVAL and Oxford ALVAL scores reproducible?

Methods The periprosthetic tissue of 37 revisions of 36 patients with failed MoM THAs were independently scored by three experienced pathologists using ALVAL and Oxford ALVAL scoring methods. All patients were included who underwent revision surgery in our hospital until January 2013, with a large-head MoM prosthesis and also met the criteria: blood serum cobalt levels, available MRI scan, and intraarticular cobalt levels. The population included 26 patients with pseudotumors diagnosed by two radiologists using the method described by Matthies et al. The ALVAL describes morphologic features of the synovial lining, tissue organization, and inflammatory cell infiltrate in periprosthetic tissues. The Oxford-ALVAL score uses a semiquantitative measure of the immune response which should be easier to score.

Results The ALVAL score showed an ICC of 0.38 (95\% CI, 0.18-0.58) (fair) for the sum score and this improved up to 0.50 (95\% CI, 0.31-0.68) (moderate) using the modified Oxford ALVAL score. The individual parameters of the ALVAL score showed an ICC for the scoring of

\section{A. H. G. Cleven}

Department of Pathology, Leiden University Medical Centre, Leiden, The Netherlands

C. Smeekes, B. C. H. van der Wal, B. F. Ongkiehong Department of Orthopaedics, Meander Medical Centre, Amersfoort, The Netherlands

S. V. Dubois, R. W. Rouse

Department of Pathology, Meander Medical Centre, Amersfoort, The Netherlands

R. Wolterbeek

Department of Medical Statistics and Bioinformatics, Leiden University Medical Centre, Leiden, The Netherlands 
inflammatory infiltrate of 0.37 (95\% CI, 0.17-0.57), an ICC of 0.32 (95\% CI, 0.12-0.53) for the scoring of tissue organization, and an ICC of 0.14 (95\% CI, -0.04 to 0.34 ) for synovial lining.

Conclusions Scoring morphologic features of MoM tissue is not reproducible using the ALVAL score or the Oxford ALVAL score. This may reflect heterogeneous morphologic features in tumor tissue and between different tumor tissue samples that cannot be reliably quantified by pathologists using the parameters of these two scoring methods. An alternative, simplified scoring system should be developed to improve the interrater agreement.

Level of Evidence Level III, diagnostic study.

\section{Introduction}

Despite hopes that metal-on-metal (MoM) bearings would provide long-lasting pain relief and restoration of function in THAs, revision rates for many designs have been alarmingly high. Release of metal ions and particles from the MoM bearing leads to elevated high local and systemic exposure to cobalt and chromium ion levels. At the local level, pseudotumor is a frequent finding, described as development of a cystic solid mass in the periarticular region, which has a direct communication with the joint [14]. A possible explanation for the occurrence of pseudotumors and failure of the MoM THA is the toxicity of the local metal debris rich in cobalt particles that can induce DNA damage and cell death, which occurs either by disruption of the membrane or because of the DNA damage. An inflammatory mass develops in response to the cytokines released [10]. Although pseudotumors also are seen in patients after conventional THA with ceramic-onpolyethylene [3] and are described in case reports of metalon-polyethylene [17, 21], risk for development of these pseudotumors is increased in patients with elevated serum metal ion levels [4].

Aseptic lymphocyte vasculitis-associated lesion (ALVAL), first reported by Davies et al. [8], is a histologic description made from tissue sampling at the time of surgery identifying an abundance of lymphocytes in the local pericapsular tissue. ALVAL typically is associated with local metal ion release. A meta-analysis showed a pooled estimate of the incidence of pseudotumor or ALVAL in MoM hip articulations to be $0.6 \%$ [30], and another study showed up to $6.5 \%$ ALVAL [16]. The most-used description method of periprosthetic tissues around MoM hip implants is the ALVAL score of Campbell et al. [7]. This subsequently was modified by Grammatopoulos et al. [12], (herein referred to as the Oxford ALVAL) to be able to distinguish if the inflammatory changes and tissue necrosis seen in periprosthetic tissues around failed MoM hip resurfacing implants are attributable to cytotoxicity or hypersensitivity tissue necrosis, and the extent of the inflammatory cell infiltrate was included. Both scoring systems are widely used [6, 9, 15, 22-24, 26, 27], however to our knowledge, other than the initial studies [7, 12], no other studies have reported on interrater reliability. Thus, it is unclear if these scoring instruments are reproducible.

We therefore asked whether the ALVAL and Oxford ALVAL scores were reproducible.

\section{Patients and Methods}

Between February 2008 and January 2011, a series of 377 uncemented primary MoM THAs with a M2a- $38^{\mathrm{TM}}$ and Taperloc $\mathbb{R}$ stem combination (Biomet, Warsaw, IN, USA) were performed at the Meander Medical Centre. During that period, we used this implant when there was an indication for a THA. Of the patients who were treated with this approach, nine patients $(3 \%)$ had died, three $(1 \%)$ were lost to followup, and four (1\%) underwent revision surgery before the screening protocol (two infections, one periprosthetic fracture, and one because of pain and subluxations). Three hundred thirty-five patients (361 hips; $95 \%$ ) were available for followup at a minimum of 11 months (mean, 30 months; range, 11-58 months) [28]. After the first concerns of MoM THA and an alert issued by the Dutch Orthopaedic Association, all patients were subjected to a screening protocol. For the current study, patients who underwent revision surgery because of failure of their MoM hip prostheses were included. A total of 71 revisions were performed in 70 patients. Twenty revisions were not MoM related. Fifty-one revisions were related to MoM problems. Of these, 36 patients with 37 revisions (one bilateral) were selected for the current study because tissue samples, intraarticular cobalt values, and MR images were available. One patient had bilateral MoM THA and underwent revision on both sides; 10 patients had bilateral MoM THAs and underwent revision on one side; and all other patients underwent revision on their unilateral MoM THA. The mean age of the patients at primary surgery was 62 years (SD, 8.2 years); 29 patients were women. The main reason for primary surgery was osteoarthritis (Table 1). The mean serum cobalt level was $20 \mu \mathrm{g} / \mathrm{L}$ (SD, $33 \mu \mathrm{g} / \mathrm{L}$ ) and the mean intraarticular fluid cobalt was 2240 $\mu \mathrm{g} / \mathrm{L}(\mathrm{SD}, 2689 \mu \mathrm{g} / \mathrm{L}$ ) (Table 1). Pain was reported by 28 patients $(76 \%)$.

Twenty-six pseudotumors were diagnosed on MRI. Most of the pseudotumors were described as $2 \mathrm{~A}$ according to the classification described by Matthies et al. [18] ( $\mathrm{n}=$ 24). Two Type 3 pseudotumors were diagnosed (Table 1). 
Table 1. Clinical data

\begin{tabular}{ll}
\hline Demographics & Mean (SD) \\
\hline Mean age at primary surgery (years) & $62(8)$ \\
Sex & \\
Male & $8(22 \%)$ \\
Female & $29(78 \%)$ \\
BMI $\left(\mathrm{kg} / \mathrm{m}^{2}\right)$ & $28(4)$ \\
Time until revision surgery (months) & $36(9)$ \\
Reasons for surgery & \\
Osteoarthritis & $33(89 \%)$ \\
Secondary osteoarthritis & $3(8 \%)$ \\
Necrosis of the femoral head & $1(3 \%)$ \\
Serum cobalt $(\mu \mathrm{g} / \mathrm{L})$ & $20(33)$ \\
Intraarticular cobalt $(\mu \mathrm{g} / \mathrm{L})$ & $2240(2689)$ \\
Pseudotumor classification $[18]$ & \\
0 & 0 \\
1 & 0 \\
$2 \mathrm{~A}$ & 24 \\
$2 \mathrm{~B}$ & 0 \\
3 & 2 \\
\hline
\end{tabular}

Reasons for revision were pseudotumor formation in combination with pain and elevated serum levels of cobalt or pain and elevated serum cobalt levels without pseudotumor formation and failure of the hip for other reasons (acetabular loosening $[\mathrm{n}=2]$ and component impingent [n $=1$ ]; these patients also had elevated cobalt levels). During revision surgery two to three samples were taken by the surgeon of the spots which were macroscopically affected by MoM disease. Each sample was formalin-fixed, paraffin-embedded, and sectioned. Slides were stained with standard hematoxylin and eosin. Sample slides (three to four for each patient) were independently examined by three pathologists (AHGC, RWR, SVD) who were experienced in diagnosing skeletal and soft tissue related diseases, and thus well trained in recognizing different types of inflammation cells and patterns of inflammation. These pathologists independently evaluated the tissue samples using the ALVAL score [7] and the adapted Oxford ALVAL scoring method [12]. The total scores of each pathologist are shown in a supplemental appendix (Appendix 1. Supplemental materials are available with the online version of $C O R R^{\circledR}$.) that shows the distribution of low, moderate, or high ALVAL scores were comparable among the pathologists. The slides were scored with the ALVAL score as described by Campbell et al. [7] and the modifications of the Oxford ALVAL by Grammatopoulos et al. [12] (Table 2). All three pathologists were blinded to the clinical outcome. The intraclass correlation coefficient (ICC) was obtained from the individual parameter scores.

The scientific committee of the Leiden University Medical Centre and the ethical committee in the Meander Medical Centre waived approval for the human protocol for this investigation, because the removed tissue was sent for routine histopathologic analysis. Because revision surgery had to be performed at such a short followup and because scientific concerns were present regarding the tissue reactions potentially caused by the MoM articulation, performing a histopathologic analysis was considered part of good clinical practice.

During the outpatient clinic visit, patients answered a standard clinical questionnaire (pain: yes or no) and underwent a physical examination. Blood samples were collected in a metal-free container. Serum cobalt was determined with the use of an Aanalyst ${ }^{\mathrm{TM}} 800$ Atomic Absorption Spectrophotometer (PerkinElmer, Waltham, MA, USA). Cobalt serum levels between 0.04 and $0.64 \mu \mathrm{g} /$ $\mathrm{L}$ were considered normal in the general population [11]. In case of revision surgery, a sample of the intraarticular fluid was taken and the cobalt values of the fluid were determined using the AAnalyst ${ }^{\mathrm{TM}} 800$ Atomic Absorption Spectrophotometer.

A contrast-enhanced MRI of the hip region with metal artifact reducing sequences (MARS) was performed on patients with osteolysis observed on the radiograph, elevated cobalt levels greater than $5 \mu \mathrm{g} / \mathrm{L}$ (cutoff value in patients with a MoM implant [13]), or with pain. Pain was defined as either the presence or absence of any pain in the hip area reported by the patient. Patients who met these criteria received routine annual followup. A 1.5-T MRI unit (Achieva; Philips Healthcare, Best, The Netherlands) was used to obtain the MARS sequences. As a contrast agent, Dotarem ${ }^{\circledR}$ (Guerbet, Paris, France) was used.

All MRI scans were evaluated by a senior musculoskeletal radiologist $(\mathrm{MN})$ and a resident in radiology (BS) with expertise in musculoskeletal disease. The criteria of the Anderson et al. [2], Hauptfleisch et al. [14], and Matthies et al. [18] classifications were used. These criteria were periprosthetic soft tissue mass or fluid-filled periprosthetic cavities and their diameter; the thickness and regularity of the wall; muscle atrophy; edema or bone marrow edema, and tendon avulsion or fracture of the bone. The classification of Anderson et al. [2] is based on their experience regarding how the MRI appeared to influence management of patients with a pseudotumor. The classifications of Matthies et al. [18] and Hauptfleisch et al. [14] are based on radiologic findings to classify the pseudotumor. In the results, the classification of Matthies et al [18] was used to describe the findings because it provided the best ICC (0.49) in our cohort. 
Table 2. Scoring of the histologic findings

\begin{tabular}{|c|c|}
\hline Scoring & Points \\
\hline \multicolumn{2}{|l|}{ Synovial lining (ALVAL) } \\
\hline Intact synovial lining & 0 \\
\hline Focal loss of synovial surface, fibrin attachment may occur & 1 \\
\hline Moderate to marked loss of synovial surface, fibrin attachment & 2 \\
\hline Complete loss of synovium, abundant attached fibrin and/or necrosis of lining tissue & 3 \\
\hline \multicolumn{2}{|l|}{ Inflammatory infiltrate (ALVAL) } \\
\hline Minimal inflammatory cell infiltrates & 0 \\
\hline Predominantly macrophages, occasional lymphocytes may occur & 1 \\
\hline Mix of macrophages and lymphocytes, either diffuse and/or small $(<50 \%$ of hpf $)$ perivascular aggregates & 2 \\
\hline Mix of macrophages and lymphocytes, large ( $>50 \% \mathrm{hpf}$ ) perivascular aggregates may occur & 3 \\
\hline Predominantly lymphocytes, mostly in multiple, large $(>50 \% \mathrm{hpf})$ perivascular aggregates, follicles may be present & 4 \\
\hline \multicolumn{2}{|l|}{ Tissue organization (ALVAL) } \\
\hline Normal tissue arrangement & 0 \\
\hline Mostly normal tissue arrangement, small areas of synovial hyperplasia, focal necrosis may occur & 1 \\
\hline Marked loss of normal arrangement, appearance of distinct cellular and acellular zones, thick fibrous layers may occur & 2 \\
\hline Perivascular lymphocytic aggregates mostly located distally, thick acellular areas may occur & 3 \\
\hline \multicolumn{2}{|l|}{ Inflammatory cells (macrophages), (lymphocytes), (plasma cells), (eosinophil polymorphs) (Oxford ALVAL) } \\
\hline Absent & 0 \\
\hline Few & $1+$ \\
\hline Many & $2+$ \\
\hline Abundant & $3+$ \\
\hline \multicolumn{2}{|l|}{ Necrosis (Oxford ALVAL) } \\
\hline Absent & 0 \\
\hline Scattered small necrotic areas & $1+$ \\
\hline Frequent small or large necrotic areas with up to $25 \%$ tissue involvement & $2+$ \\
\hline Extensive necrosis with $>25 \%$ tissue necrosis & $3+$ \\
\hline \multicolumn{2}{|l|}{ Oxford ALVAL score (semiquantitative score) } \\
\hline No evidence of a perivascular lymphocyte infiltrate & 0 \\
\hline Little evidence of a perivascular lymphocytic infiltrate with lymphocyte cuffing of blood vessels being fewer than five cells in thickness & 1 \\
\hline Several perivascular lymphoid aggregates with lymphocyte cuffing of vessels being five to 10 cells in thickness & 2 \\
\hline Numerous large perivascular lymphoid aggregates with lymphocyte cuffing around vessels being more than 10 cells in thickness & 3 \\
\hline
\end{tabular}

The original ALVAL score [7] uses the first three categories (synovial lining, inflammatory infiltrate, and tissue organization); the Oxford scoring system [12] assesses tissue necrosis and the extent of the inflammatory cell infiltrate in the periprosthetic tissues. The presence of specific inflammatory cells (macrophages, lymphocytes, plasma cells, eosinophil polymorphs) was noted, and the presence or absence of an ALVAL response was assessed semiquantitatively as previously described. In the current study all parameters are scored; the number of specific inflammatory cells is scored as 0 (absent), 1 (few), 2 (many), or 3 (abundant). Necrosis was scored as 0 (absent), 1 (scattered small necrotic areas), 2 (frequent small or large necrotic areas with up to $25 \%$ tissue involvement), or 3 (extensive necrosis with $>25 \%$ tissue involvement); ALVAL = aseptic lymphocyte vasculitis-associated lesion; hpf $=$ high-power field.

The original ALVAL scoring system described by Campbell et al. [7] uses three different histologic criteria: synovial lining, inflammatory infiltrate, and tissue organization, which add up to an overall score. The modified Oxford ALVAL scoring system described by Grammatopoulos et al. [12] adds tissue necrosis and the extent of the inflammatory cell infiltrate in the periprosthetic tissues. The presence of specific inflammatory cells (macrophages, lymphocytes, plasma cells, eosinophil polymorphs) is noted and the ALVAL response is rated semiquantitatively (Table 2).

\section{Statistical Analysis}

Descriptive analyses were performed on final outcomes. The results are expressed as means with SD or medians with ranges where relevant.

The interobserver reliability was calculated as an ICC with a $95 \%$ CI based on a two-way random-ANOVA with patient and pathologist as random factors for three pathologists. This ICC has an interpretation as a weighted kappa with quadratic weights. 
The ICC value for agreement was interpreted as follows: poor $<0.20$; fair, 0.21 to 0.40 ; moderate, 0.41 to 0.60 ; good, 0.61 to 0.80 ; and very good, 0.81 to 1.0 [5]. SPSS Statistics Version 20.0 (IBM Corporation, Armonk, NY, USA) was used for the analysis.

\section{Results}

The ICC for the sum score using the ALVAL classification is 0.38 (95\% CI, 0.18-0.58), which is categorized as fair. The individual parameters of this score show an ICC for the scoring of inflammatory infiltrate of $0.37(95 \% \mathrm{CI}$, $0.17-0.57)$, an ICC of $0.32(95 \% \mathrm{CI}, 0.12-0.53)$ for the scoring of tissue organization, and an ICC of $0.12(95 \% \mathrm{CI}$, 0.00-0.34) for synovial lining (Table 3 ). The ICC for the

Table 3. Intraclass correlation coefficients of the morphologic features of the scoring

\begin{tabular}{ll}
\hline Morphologic features & $\begin{array}{l}\text { Intraclass correlation }(95 \% \\
\mathrm{CI})\end{array}$ \\
\hline Synovial lining & $0.12(0.00-0.34)$ \\
Inflammatory infiltrate & $0.37(0.17-0.57)$ \\
Tissue organization & $0.32(0.12-0.53)$ \\
Sum score & $0.38(0.18-0.58)$ \\
Inflammatory cells (macrophages) & $0.44(0.24-0.64)$ \\
Inflammatory cells (lymphocytes) & $0.50(0.29-0.68)$ \\
Inflammatory cells (plasma cells) & $0.29(0.09-0.50)$ \\
Inflammatory cells (eosinophil & $0.04(0.00-0.24)$ \\
$\quad$ polymorphs) & $0.37(0.17-0.58)$ \\
Necrosis & $0.50(0.30-0.68)$ \\
\hline
\end{tabular}

ALVAL $=$ aseptic lymphocyte vasculitis-associated lesion.

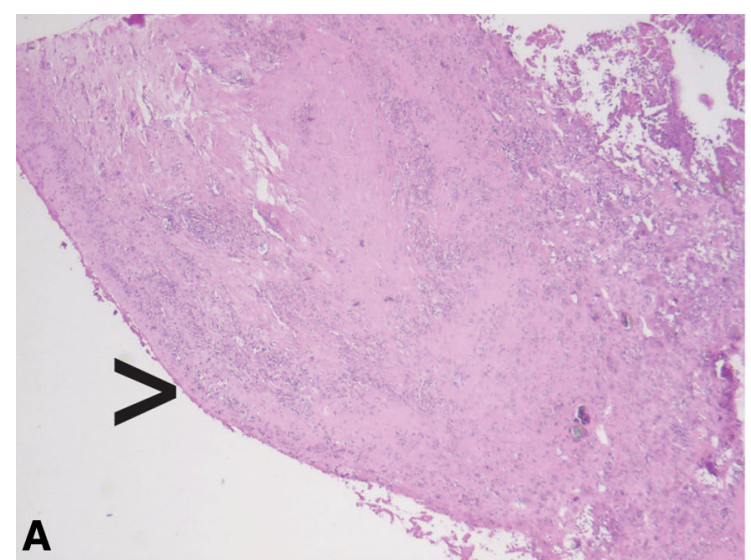

Fig. 1A-B Histologic analyses of hematoxylin and eosin-stained sections at $(\mathbf{A}) \times 2.5$ magnification and $(\mathbf{B}) \times 10$ magnification show the morphologic spectrum in discordant cases with no dense sum score using the Oxford ALVAL score is 0.50 (95\% CI, $0.30-0.68$ ), which is categorized as moderate. The scoring of inflammatory cells and necrosis showed ICC between 0.04 (95\% CI, 0.00-0.24) and 0.50 (95\% CI, 0.29-0.68). The highest ICC, 0.50 (95\% CI, 0.29-0.68) was found for inflammatory cells (lymphocytes) (Table 3). Heterogeneous morphologic features in a discordant case with no dense lymphocytic infiltrate and areas with no intact synovial lining with fibrin attachment (Fig. 1) and in a discordant case with dense perivascular lymphocytic aggregates (Fig. 2) are shown.

\section{Discussion}

MoM THAs have a high failure rate [29]. Elevated serum cobalt levels, pseudotumors, and tissue reaction have been described [13, 14, 31]. Pathologic findings in patients with failed MoM THAs have been described using the ALVAL and Oxford ALVAL scoring methods [7, 12]. Only the initial studies [7, 12] report ICC values for interobserver reliability. In the current study, we tested the reproducibility of these scoring systems by three independent pathologists. The scoring system of Campbell et al. [7] showed an ICC of 0.38 (95\% CI, 0.18-0.58) for the sum score, which is rated as fair. The sum score improved up to 0.5 (95\% CI, 0.30-0.68) using the modified Oxford ALVAL score [12].

This study had several limitations. Only one type of implant was used, which might not be characteristic of other MoM devices. The selection for revision surgery was made by using the described screening method. All patients who underwent revision surgery were symptomatic and most of the patients had high cobalt serum levels. Thus, our findings may not be applicable to patients with different

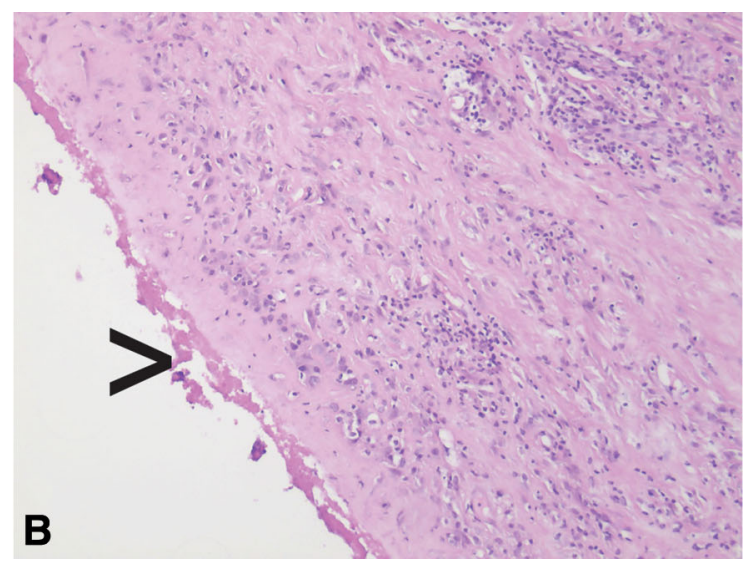

lymphocytic infiltrate and areas with no intact synovial lining with fibrin attachment (black arrows). 



Fig. 2A-B Histologic analyses of hematoxylin and eosin-stained sections at (A) $\times 2.5$ magnification and (B) $\times 10$ magnification show discordant cases with dense perivascular lymphocytic aggregates (black arrows)

presentations, such as asymptomatic patients with concerning MRI and laboratory findings. No prelearning meeting with all three pathologists was done to describe how to score the tissue slides using the scoring methods. Nevertheless all pathologists are experienced in diagnosing skeletal and soft tissue-related diseases, and thus well trained in recognizing different types of inflammation cells and patterns of inflammation. We believe that the poor ICCs we found in our study regarding the ALVAL and Oxford ALVAL scores are attributable to the complex, and therefore not reproducible, scoring methods rather than expert level of individual pathologists. We had a relatively small sample size, meaning that we might not have detected a truly high level of reliability. However, the studies reporting the original ALVAL [7] and Oxford ALVAL [12] scores were based on 32 and 65 samples, respectively.

Although the modified classification system improves the ICC value, it is still no more than moderate. A moderate score indicates inadequate interrater agreement and study results are not reliable to draw any definitive conclusions [5, 19]. Our low ICC values for the individual parameters (inflammatory cells and necrosis) varying between 0.04 and 0.50 underline the low reproducibility of these morphologic findings. In contrast to our results, Campbell et al. [7] reported an interrater reliability of 0.71 and Grammatopoulos et al. [12] reported interrater reliability of 0.74 . The ICCs of the ALVAL and the Oxford ALVAL was scored by two observers in these original studies.

Despite that the ALVAL and Oxford ALVAL scoring methods are not well validated, these scoring systems were used in other studies without reporting ICC values $[6,9,15$, 22-24, 26, 27]. These study results should be interpreted with caution. Our results clearly illustrate that the ALVAL and Oxford ALVAL scoring systems are not reproducible in our hands, and therefore we believe that clinicians should not use these scoring methods. Larger cohorts are required for the development of an alternative, more-simplified scoring method. Multiple pathologists should score a set of cases to investigate how well the new scoring method is reproducible. Digital imaging analysis showed good results in liver fibrosis [25], in assessing digital ulcers in patients with systemic sclerosis [1], and in analysis of cancer stem cell marker expression [20]. This type of tissue analysis might be a good alternative for scoring of MoM periprosthetic tissue.

If this scoring method is reproducible, correlation with clinically meaningful data should be performed.

Acknowledgments We thank Bart J.M. Schouten MD (Department of Radiology and Nuclear Medicine, Maasstad Hospital, Rotterdam, the Netherlands) and Maarten Nix MD (Department of Radiology, Meander Medical Centre, Amersfoort, the Netherlands) for evaluating all MR images and using the different radiologic classification systems.

Open Access This article is distributed under the terms of the Creative Commons Attribution 4.0 International License (http:// creativecommons.org/licenses/by/4.0/), which permits unrestricted use, distribution, and reproduction in any medium, provided you give appropriate credit to the original author(s) and the source, provide a link to the Creative Commons license, and indicate if changes were made.

\section{References}

1. Ahrens HC, Siegert E, Tomsitz D, Mattat K, March C, Worm M, Riemekasten G. Digital ulcers score: a scoring system to assess digital ulcers in patients suffering from systemic sclerosis. Clin Exp Rheumatol. 2016;34(suppl 100):142-147.

2. Anderson H, Toms AP, Cahir JG, Goodwin RW, Wimhurst J, Nolan JF. Grading the severity of soft tissue changes associated with metal-on-metal hip replacements: reliability of an MR grading system. Skeletal Radiol. 2011;40:303-307. 
3. Bisseling P, de Wit BW, Hol AM, van Gorp MJ, van Kamp A, van Susante JL. Similar incidence of periprosthetic fluid collections after ceramic-on-polyethylene total hip arthroplasties and metal-on-metal resurfacing arthroplasties: results of a screening metal artefact reduction sequence-MRI study. Bone Joint J. 2015;97:1175-1182.

4. Bosker BH, Ettema HB, Boomsma MF, Kollen BJ, Maas M, Verheyen CC. High incidence of pseudotumour formation after large-diameter metal-on-metal total hip replacement: a prospective cohort study. J Bone Joint Surg Br. 2012;94:755-761.

5. Brennan P, Silman A. Statistical methods for assessing observer variability in clinical measures. BMJ. 1992;304:1491-1494.

6. Burge AJ, Gold SL, Lurie B, Nawabi DH, Fields KG, Koff MF, Westrich G, Potter HG. MR imaging of adverse local tissue reactions around Rejuvenate modular dual-taper stems. Radiology. 2015;277:142-150.

7. Campbell P, Ebramzadeh E, Nelson S, Takamura K, De Smet K, Amstutz HC. Histological features of pseudotumor-like tissues from metal-on-metal hips. Clin Orthop Relat Res. 2010;468:2321-2327.

8. Davies AP, Willert HG, Campbell PA, Learmonth ID, Case CP. An unusual lymphocytic perivascular infiltration in tissues around contemporary metal-on-metal joint replacements. J Bone Joint Surg Am. 2005;87:18-27.

9. Ebramzadeh E, Campbell P, Tan TL, Nelson SD, Sangiorgio SN. Can wear explain the histological variation around metal-onmetal total hips? Clin Orthop Relat Res. 2015;473:487-494.

10. Gill HS, Grammatopoulos G, Adshead S, Tsialogiannis E, Tsiridis E. Molecular and immune toxicity of $\mathrm{CoCr}$ nanoparticles in MoM hip arthroplasty. Trends Mol Med. 2012;18:145-155.

11. Goulle JP, Mahieu L, Castermant J, Neveu N, Bonneau L, Laine G, Bouige D, Lacroix C. Metal and metalloid multi-elementary ICP-MS validation in whole blood, plasma, urine and hair: reference values. Forensic Sci Int. 2005;153:39-44.

12. Grammatopoulos G, Pandit H, Kamali A, Maggiani F, GlynJones S, Gill HS, Murray DW, Athanasou N. The correlation of wear with histological features after failed hip resurfacing arthroplasty. J Bone Joint Surg Am. 2013;95:e81.

13. Hart AJ, Sabah SA, Bandi AS, Maggiore P, Tarassoli P, Sampson B, Skinner JA. Sensitivity and specificity of blood cobalt and chromium metal ions for predicting failure of metal-on-metal hip replacement. J Bone Joint Surg Br. 2011;93:1308-1313.

14. Hauptfleisch J, Pandit H, Grammatopoulos G, Gill HS, Murray DW, Ostlere S. A MRI classification of periprosthetic soft tissue masses (pseudotumours) associated with metal-on-metal resurfacing hip arthroplasty. Skeletal Radiol. 2012;41:149-155.

15. Kolatat K, Perino G, Wilner G, Kaplowitz E, Ricciardi BF, Boettner F, Westrich GH, Jerabek SA, Goldring SR, Purdue PE. Adverse local tissue reaction (ALTR) associated with corrosion products in metal-on-metal and dual modular neck total hip replacements is associated with upregulation of interferon gamma-mediated chemokine signaling. $J$ Orthop Res. 2015;33:1487-1497.

16. Korovessis P, Petsinis G, Repanti M, Repantis T. Metallosis after contemporary metal-on-metal total hip arthroplasty: five to nineyear follow-up. J Bone Joint Surg Am. 2006;88:1183-1191.

17. Mao X, Tay GH, Godbolt DB, Crawford RW. Pseudotumor in a well-fixed metal-on-polyethylene uncemented hip arthroplasty. $J$ Arthroplasty. 2012;27:493.e13-e17.
18. Matthies AK, Skinner JA, Osmani H, Henckel J, Hart AJ. Pseudotumors are common in well-positioned low-wearing metal-on-metal hips. Clin Orthop Relat Res. 2012;470:18951906.

19. McHugh ML. Interrater reliability: the kappa statistic. Biochem Med (Zagreb). 2012;22:276-282.

20. Miller TJ, McCoy MJ, Hemmings C, Bulsara MK, Iacopetta B, Platell CF. Objective analysis of cancer stem cell marker expression using immunohistochemistry. Pathology. 2017;49:2429.

21. Murgatroyd SE. Pseudotumor presenting as a pelvic mass: a complication of eccentric wear of a metal on polyethylene hip arthroplasty. J Arthroplasty. 2012;27:820.e1-4.

22. Nawabi DH, Do HT, Ruel A, Lurie B, Elpers ME, Wright T, Potter HG, Westrich GH. Comprehensive analysis of a recalled modular total hip system and recommendations for management. J Bone Joint Surg Am. 2016;98:40-47.

23. Nawabi DH, Gold S, Lyman S, Fields K, Padgett DE, Potter HG. MRI predicts ALVAL and tissue damage in metal-on-metal hip arthroplasty. Clin Orthop Relat Res. 2014;472:471-481.

24. Nawabi DH, Nassif NA, Do HT, Stoner K, Elpers M, Su EP, Wright T, Potter HG, Padgett DE. What causes unexplained pain in patients with metal-on metal hip devices? A retrieval, histologic, and imaging analysis. Clin Orthop Relat Res. 2014;472:543-554.

25. Pavlides M, Birks J, Fryer E, Delaney D, Sarania N, Banerjee R, Neubauer S, Barnes E, Fleming KA, Wang LM. Interobserver variability in histologic evaluation of liver fibrosis using categorical and quantitative scores. Am J Clin Pathol. 2017;147:364369.

26. Phillips EA, Klein GR, Cates HE, Kurtz SM, Steinbeck M. Histological characterization of periprosthetic tissue responses for metal-on-metal hip replacement. $J$ Long Term Eff Med Implants. 2014;24:13-23.

27. Reito A, Parkkinen J, Puolakka T, Pajamaki J, Eskelinen A. Diagnostic utility of joint fluid metal ion measurement for histopathological findings in metal-on-metal hip replacements. BMC Musculoskelet Disord. 2015;16:393.

28. Smeekes C, Ongkiehong B, van der Wal B, Wolterbeek R, Henseler JF, Nelissen R. Large fixed-size metal-on-metal total hip arthroplasty: higher serum metal ion levels in patients with pain. Int Orthop. 2015;39:631-638.

29. Smith AJ, Dieppe P, Vernon K, Porter M, Blom AW; National Joint Registry of England and Wales. Failure rates of stemmed metal-on-metal hip replacements: analysis of data from the National Joint Registry of England and Wales. Lancet. 2012;379:1199-1204.

30. Wiley KF, Ding K, Stoner JA, Teague DC, Yousuf KM. Incidence of pseudotumor and acute lymphocytic vasculitis associated lesion (ALVAL) reactions in metal-on-metal hip articulations: a meta-analysis. J Arthroplasty. 2013;28:12381245.

31. Willert HG, Buchhorn GH, Fayyazi A, Flury R, Windler M, Koster G, Lohmann CH. Metal-on-metal bearings and hypersensitivity in patients with artificial hip joints: a clinical and histomorphological study. J Bone Joint Surg Am. 2005;87:28-36. 